\title{
Reduced Transport Potential of a Palladium-doped Zero Valent Iron Nanoparticle in a Water Saturated Loamy Sand
}

\author{
Revised and Re-submitted to: \\ Water Research \\ September 19, 2014
}

\author{
MOHAN BASNET ${ }^{1}$, CAROLINE DI TOMMASO ${ }^{1}$, SUBHASIS GHOSHAL ${ }^{2}$, and \\ NATHALIE TUFENKJI', 1
}

${ }^{1}$ Department of Chemical Engineering, McGill University, Montreal, Quebec H3A 0C5, Canada ${ }^{2}$ Department of Civil Engineering, McGill University, Montreal, Quebec H3A 0C3, Canada

Corresponding Author:

Nathalie Tufenkji

Department of Chemical Engineering

McGill University

3610 University St.

Montreal, Quebec, H3A 0C5

Phone: (514) 398-2999; Fax: (514) 398-6678; E-mail: nathalie.tufenkji@mcgill.ca 


\begin{abstract}
Direct in situ injection of palladium-doped nanosized zero valent iron (Pd-NZVI) particles can contribute to remediation of various environmental contaminants. A major challenge encountered is rapid aggregation of Pd-NZVI and hence very limited mobility. To reduce aggregation and concurrently improve particle mobility, the surface of bare Pd-NZVI can be modified with stabilizing surface modifiers. Selected surface-modified Pd-NZVI has shown dramatically improved stability and transport. However, little is known regarding the effects of aquifer grain geochemical heterogeneity on the transport and deposition behavior of surface-modified Pd-NZVI. Herein, the mobility of surface stabilized Pd-NZVI in two granular matrices representative of model ground water environments (quartz sand and loamy sand) was assessed over a wide range of environmentally relevant ionic strengths (IS). Carboxymethyl cellulose (CMC), soybean flour and rhamnolipid biosurfactant were used as Pd-NZVI surface modifiers. Our results show that, both in quartz sand and loamy sand, an increase in solution IS results in reduced Pd-NZVI transport. Moreover, at a given water chemistry, Pd-NZVI transport is notably attenuated in loamy sand implying that geochemical heterogeneity associated with loamy sand is a key factor influencing Pd-NZVI transport potential. Experiments conducted at a higher Pd-NZVI particle concentration, to be more representative of field conditions, show that rhamnolipid and CMC are effective stabilizing agents even when $1 \mathrm{~g} / \mathrm{L} \mathrm{Pd-NZVI}$ is injected into quartz sand. Overall, this study emphasizes the extent to which variation in groundwater chemistry, coupled with changes in aquifer geochemistry, could dramatically alter the transport potential of Pd-NZVI in the subsurface environment.
\end{abstract}

Keywords: nanoparticle transport, nanoparticle deposition, surface modifiers, zerovalent iron, loamy sand 


\section{Introduction}

Palladium-doped nanosized zero valent iron (Pd-NZVI) particles are highly efficient for the transformation of various environmental contaminants into innocuous products via redox reactions (Zhang, 2003). The direct injection of Pd-NZVI into contaminated aquifers has been suggested as a promising technique for achieving rapid remediation (Tratnyek and Johnson, 2006). Success of this in situ remediation technique depends on effective subsurface delivery of the reactive Pd-NZVI particles to the contaminant of interest. However, rapid particle aggregation and resultant limited mobility have been reported to be a major challenge in the implementation of this technology (Phenrat et al., 2006). Therefore, to reduce aggregation and concurrently improve transport, bare Pd-NZVI is coated with stabilizing surface modifiers (Saleh et al., 2007). Furthermore, once injected for the targeted subsurface application, the particle may experience various physical transformations such as aggregation, heteroaggregation with other colloids, deposition on collector (grain) surfaces, as well as changes to the surface chemistry resulting from reactions in the aqueous environment (Kim et al., 2012; Lowry et al., 2012; Phenrat et al., 2010; Phenrat et al., 2009). Particle-particle interactions leading to aggregation can have several important consequences. First, an increase in particle size due to aggregation may influence particle deposition by altering the magnitude of colloidal forces between the particles and interacting grain surfaces (Petosa et al., 2010). Second, particle aggregates may be more prone to particle retention by physical straining or wedging (Johnson et al., 2007). Physical straining has been shown to be an influencing factor limiting NZVI transport, especially for bare (Pd-)NZVI (Basnet et al., 2013; Saleh et al., 2007). (Raychoudhury et al., 2014) report that straining can be an important retention mechanism even for polymer-stabilized NZVI. The presence of stabilizing polymers on the surface of (Pd-)NZVI can reduce both the extent of aggregation and deposition, 
the effectiveness of which depends on the type of modifier selected (Fatisson et al., 2010; Saleh et al., 2008). While different surface modifiers demonstrate varied stabilizing efficiency, the effectiveness of the modifier could depend on the geochemistry of the site to be remediated. We have previously shown good colloidal stability and enhanced transport in quartz sand of Pd-NZVI coated with CMC, rhamnolipid biosurfactant and soy protein (Basnet et al., 2013). We showed that when particle aggregation is unfavorable (i.e., in the presence of repulsive particle-particle interactions), all of the selected surface modifiers performed well to improve Pd-NZVI mobility. However, at high ionic strength when aggregation is favorable (i.e., in the absence of repulsive interactions), rhamnolipid was more efficient at enhancing Pd-NZVI transport in quartz sand (Basnet et al., 2013).

A number of previous studies examined the transport and deposition behavior of nanoparticles in quartz sand (Kanel et al., 2007; Kocur et al., 2013; Saleh et al., 2008; Schrick et al., 2004; Tiraferri and Sethi, 2009); however, only few studies have investigated nanoparticle transport in granular matrices other than quartz sand (Cornelis et al., 2013; Jaisi and Elimelech, 2009; Laumann et al., 2014; Petosa et al., 2013; Quevedo and Tufenkji, 2012; Zhao et al., 2012). Aquifer materials can vary considerably with respect to mineral surface chemistry and grain size distribution and nanoparticle transport is expected to change significantly in different granular environments. For example, comparable transport behavior was observed for two types of quantum dots in quartz sand (Quevedo and Tufenkji, 2012). However, these nanoparticles exhibited different transport behavior in loamy sand, and this was attributed to the variable affinity of the nanoparticle surface coatings to the clay surfaces in the loamy sand. Such an influence of clay was also reported for $\mathrm{ZnO}$ nanoparticles whereby increased particle retention was observed in sandy loam soil (Zhao et al., 2012). Another study comparing the transport potential of cerium dioxide 
nanoparticles in quartz sand to that in loamy sand demonstrated enhanced retention in the loamy sand, which was attributed to the presence of clays such as allophane and metallic impurities in the loamy sand (Petosa et al., 2013).

Although the surface modification of (Pd-)NZVI has been extensively studied in recent years (Basnet et al., 2013; Phenrat et al., 2008; Tiraferri et al., 2008), their transport potential in the subsurface environment remains unclear, especially through complex matrixes that contain physical and geochemical heterogeneities. Kim et al. (2012) studied coated NZVI transport in a heterogeneous porous matrix created by adding either kaolinite clay or silica fines to quartz sand and observed greater deposition in the presence of clay minerals than with silica fines (Kim et al., 2012). They hypothesized that NZVI-kaolinite heteroaggregation was the possible mechanism for the observed increase in deposition. To design efficient NZVI remediation plans, there is a clear need for studies on the transport potential of (Pd-)NZVI in heterogeneous granular media which more closely mimic the natural environment.

The objective of this study is to compare the transport potential of bare and surfacemodified Pd-NZVI in a geochemically complex loamy sand to that in a more homogeneous quartz sand. Three types of surface modifiers were used in this study to coat the Pd-NZVI: (i) CMC, (ii) rhamnolipid biosurfactant and (iii) soybean flour. These modifiers were selected based on the effectiveness demonstrated in our previous work (Basnet et al., 2013) as well as their low cost, biodegradability, biocompatibility and commercial availability. The transport potential of PdNZVI was then assessed by conducting column experiments in two granular porous matrices: (i) quartz sand (widely used in previous studies), and (ii) loamy sand collected from a farm near Quebec City, QC. Moreover, to assess the impact of clay on the transport potential of Pd-NZVI, additional column experiments were conducted with clay-supplemented quartz sand, where the 
mass fraction of added clay was matched to that of the loamy sand. To our knowledge, this is one of the first studies which systematically examines the combined influence of grain geochemical heterogeneity and water chemistries on Pd-NZVI transport behavior. Thus, this study builds on our previous work where the transport behavior of Pd-NZVI was examined in quartz sand at only two solution IS.

\section{Materials and Methods}

\subsection{Nanoparticle Suspension Preparation}

Surface modification and nanoparticle suspension preparation methods were adopted from our previous work (Basnet et al., 2013). Details are provided in the supplementary data. Three types of anionic surface modifiers were selected as Pd-NZVI stabilizing agents: (i) the sodium salt of CMC (Sigma-Aldrich), (ii) rhamnolipid JBR215 (Jeneil Biosurfactant Co., Saukville, Wisconsin, USA), and (iii) soybean flour (SF) (Sigma-Aldrich). These surface modifiers were selected based on their effectiveness demonstrated in our earlier studies (Basnet et al., 2013; Fatisson et al., 2010). Details on the surface modifiers are presented in Table S1. The final working suspension contained $0.15 \mathrm{~g} / \mathrm{L}$ Pd-NZVI and $0.1 \mathrm{~g}$ TOC/L surface modifier. The solution IS was adjusted by adding $\mathrm{NaCl}$ and the $\mathrm{pH}$ adjusted to an environmentally relevant value of 7.7 using $\mathrm{NaOH}$.

\subsection{Nanoparticle Characterization}

Dynamic light scattering (DLS) and nanoparticle tracking analysis (NTA) were used to characterize the hydrodynamic diameter of the particles (details are provided in the Supporting Data). All characterization and transport experiments were conducted over a wide range of IS (3 $100 \mathrm{mM} \mathrm{NaCl})$. 


\subsection{Column Transport Experiments}

Bench-scale Pd-NZVI transport experiments were conducted using a glass column (GE Life Sciences) with $1.6 \mathrm{~cm}$ internal diameter and $8.1 \mathrm{~cm}$ saturated packed bed length. Three sets of column experiments were conducted: (i) in quartz sand to assess transport potential in a relatively ideal (homogeneous) medium, (ii) in loamy sand to assess the transport potential in a complex heterogeneous medium, (iii) in clay supplemented quartz sand to better understand the impact of clay. Details on the sand characteristics are included in Table S2. Prior to injecting nanoparticles, the breakthrough behavior of an inert tracer $\left(10 \mathrm{mM} \mathrm{KNO}_{3}\right)$ was monitored and used to evaluate the bed porosity (Figure S1). All column experiments were done at least in duplicate.

Quartz sand column experiments were conducted as described previously (Pelley and Tufenkji, 2008). Loamy sand column experiments were conducted as described previously with slight modification (Jaisi and Elimelech, 2009; Petosa et al., 2013). Details on procedures for the quartz sand and loamy sand column experiments are included in the Supporting Data. Particle transport was also examined using columns of clay-supplemented quartz sand. Kaolinite (Sigma) was selected as the model clay in this study. To ensure homogeneous clay distribution, a wet mixing procedure was employed (Kim et al., 2012) using $2.05 \mathrm{~g}$ of clay slurry that was first prepared in $10 \mathrm{~mL}$ DI water. The quartz sand (24.95 g) was then added into the clay slurry and mixed with a bench-top vortex at full speed for $30 \mathrm{sec}$. The resultant mixture was then dried at $100^{\circ} \mathrm{C}$ for 8 hours. The concentration of clay in the clay-supplemented quartz sand was $7.6 \%$ and corresponds to the quantity of clay in the loamy sand used herein (Quevedo and Tufenkji, 2012). The subsequent experimental procedures were identical to those used in the loamy sand column experiments. 


\subsection{Nanoparticle Transport Potential.}

Colloid filtration theory (CFT) was used to assess nanoparticle transport potential in the different granular matrices. For each experimental condition, the Pd-NZVI particle-collector attachment efficiency $\left(\alpha_{\mathrm{pc}}\right)$ was calculated using the following equation (Yao et al., 1971):

$$
\alpha_{p c}=-\frac{2}{3} \frac{d_{c}}{(1-\theta) L \eta_{0}} \ln \left(\frac{C}{C_{0}}\right)
$$

where $d_{\mathrm{c}}$ is the mean grain diameter, $\theta$ is the bed porosity, $L$ is the packed-bed length, and $\eta_{0}$ is the single-collector contact efficiency calculated using the Tufenkji-Elimelech equation (Tufenkji and Elimelech, 2004). An advantage of calculating attachment efficiency is that it may serve as a single parameter for the quantitative comparison of nanoparticle transport potential across several treatments used in one study or across several studies (conducted in different labs) that may have employed different granular materials, hydrodynamic conditions and nanoparticle sizes. However, the shortcoming of this model is that when the breakthrough curves are asymmetric and do not follow the classical CFT-type behavior, the calculated attachment efficiency may only be useful for a semi-quantitative comparison.

\section{Results and Discussion}

\subsection{Electrophoretic Mobility of Pd-NZVI}

The electrokinetic properties of bare and stabilized Pd-NZVI were evaluated by measuring PdNZVI electrophoretic mobility (EPM) in different water chemistries. The surface coatings render the particles more negatively charged over a broad range of $\mathrm{pH}$ (at $10 \mathrm{mM}$ IS) (Figure S2). Overall, at neutral $\mathrm{pH}$, all particles are negatively charged and decreases in $\mathrm{pH}$ up to the isoelectric point (IEP) generally result in a reduced absolute EPM. The IEP varies as follows (from high to low): 
bare $>$ SF-coated $>$ JBR215-coated $>$ CMC-coated Pd-NZVI. We previously confirmed adsorption of each surface modifier on the Pd-NZVI surface (Basnet et al., 2013).

The IS-dependent Pd-NZVI electrokinetic behavior at $\mathrm{pH} 7.7 \pm 0.2$ is shown in Table 1. All the particles used in column experiments are negatively charged. At $3 \mathrm{mM}$ IS, the order of influent $\mathrm{EPM}(\mu \mathrm{m} . \mathrm{cm} / \mathrm{V} . \mathrm{s})$ from less negative to more negative is: -1.9 (bare) $<-2.2(\mathrm{SF})<-3.8(\mathrm{JBR} 215)$ $<-4.5$ (CMC). At $100 \mathrm{mM}$, the absolute EPM of influent nanoparticles decreases due to more effective charge screening; the EPM $(\mu \mathrm{m} \cdot \mathrm{cm} / \mathrm{V} \cdot \mathrm{s})$ of SF-coated Pd-NZVI decreases to -1.2 which is close to bare (-1.4) whereas JBR215-coated (-2.1) and CMC-coated (-2.5) Pd-NZVI remained more negative. Finally, an inspection of Table 1 for the EPM values of particles in the influent or effluent suspension does not reveal noticeable differences. These data are in agreement with previously reported measurements (Basnet et al., 2013). It is worth noting that the EPM of bare Pd-NZVI did not vary significantly from the lowest to the highest IS.

\subsection{Sizing Analysis of Pd-NZVI}

Two light scattering techniques (DLS and NTA) were employed to characterize nanoparticle size (Table 1). To assess whether there is any size-dependent preferential particle retention in the packed matrix, DLS size (z-average hydrodynamic diameter) measurements were done for both influent and effluent suspensions. Irrespective of IS, the DLS size ( $d_{\text {DLS }}$ ) of (influent) bare PdNZVI is $>1 \mu \mathrm{m}$ although the nominal size of the Pd-NZVI particles was less than $100 \mathrm{~nm}$, as determined by TEM imaging (Figure S3). This large aggregate size can be attributed to rapid aggregation of the bare Pd-NZVI due to strong particle-particle magnetic interactions (Phenrat et al., 2006). In contrast, the effluent bare Pd-NZVI is $<1 \mu \mathrm{m}$ throughout the range of IS investigated (3-100 $\mathrm{mM}$ ) which may be explained by the preferential deposition of larger particles and/or the contribution of physical straining and/or wedging (Johnson et al., 2007) to the retention of larger 
particles $\left(d_{\text {effluent }} / d_{\text {influent }}<<1\right)$ (Figure S4). Surface modification reduces the extent of aggregation, clearly seen by much smaller $\left(d_{\mathrm{DLS}}<300 \mathrm{~nm}\right)$ (than bare) influent particle sizes for JBR215- and SF-coated Pd-NZVI at 3-100 mM IS (Table 1). For CMC-coated Pd-NZVI, the stabilizing effect is evident at low IS ( $3 \mathrm{mM})$, however the particles aggregate at higher IS, and straining/and or wedging is expected to be more important in loamy sand (Figure S4).

We also assessed the homogeneity of the suspensions used in the transport experiments. Based on the measured values of the polydispersity index (PDI) obtained from the influent suspension DLS measurements, CMC yields the most polydisperse system (PDI 0.6-0.7), followed by bare (PDI 0.4-0.6), JBR215 (PDI 0.3-0.6) and SF (PDI 0.3-0.4). A similar trend exists for the effluent suspensions as well (Table 1). A PDI value $<0.1$ reflects a relatively narrow monomodal particle size distribution (PSD) (Nobbmann et al., 2007). Therefore, all the suspensions used in the transport experiments exhibited some degree of polydispersity.

Particle sizes measured by DLS (influent) were compared to those determined by NTA $\left(d_{\mathrm{NTA}}\right)$. For bare and CMC-coated Pd-NZVI, the NTA sizes are significantly smaller than $d_{\mathrm{DLS}}$ (Table 1). This has been observed before for $\mathrm{TiO}_{2}$ and $\mathrm{ZnO}$ nanoparticles (Petosa et al., 2012) and can be attributed to the fact that DLS is very sensitive to the presence of aggregates in the suspension and generally overestimates the average size of polydisperse suspensions whereas larger particles (aggregates) have less influence on NTA measurements (Domingos et al., 2009). However, for both JBR215- and SF-coated Pd-NZVI, size measurements are comparable using the two techniques. The NTA measured percentile values $\left(d_{10}\right.$ or $\left.d_{90}\right)$ are also included in Table 1 to demonstrate the range of particle sizes prevailing in each experimental condition. Based on a comparison of $d_{10}$ to $d_{90}$ (Table 1), it is clear that (throughout the range of IS investigated) the bare Pd-NZVI exhibits a narrow size distribution, whereas the size distribution becomes broader with 
surface modification, with SF-coated Pd-NZVI displaying the widest distribution (Table 1). The narrow size distribution of bare Pd-NZVI may be explained by the rapid aggregation that occurred just prior to the start of NTA measurements.

We also measured the DLS size at the higher particle concentration of $1 \mathrm{~g} / \mathrm{L}$ (Table 1); however, NTA was not used due to limitations of the instrument in handling concentrated samples. The higher particle concentration induced severe aggregation due to increased particle-particle collisions. All the influent particle sizes were $>1 \mu \mathrm{m}$ at $1 \mathrm{~g} / \mathrm{L}$ for the different surface modified Pd-NZVI. Moreover, a comparison of DLS obtained PSD at $0.15 \mathrm{~g} / \mathrm{L}$ versus $1 \mathrm{~g} / \mathrm{L}$ clearly shows a marked shift in PSD towards larger particle size (Figure S5). It is also worth noting the monomodal PSD for bare-, JBR215- and SF-coated Pd-NZVI. In contrast, CMC-coated Pd-NZVI exhibits a bimodal PSD at $0.15 \mathrm{~g} / \mathrm{L}$ Pd-NZVI which evolves to a trimodal PSD at $1 \mathrm{~g} / \mathrm{L}$ (Figure S5). Based on the PSDs, at $0.15 \mathrm{~g} / \mathrm{L}$, the efficiency of the stabilizers in reducing aggregation ranks

as follows: JBR215 $\approx \mathrm{SF}>\mathrm{CMC}$. At $1 \mathrm{~g} / \mathrm{L}$, marked aggregation occurs; however, based on the PSDs we can infer the stabilizing effects in the following order: JBR215>SF>CMC.

\subsection{Pd-NZVI Transport in Quartz Sand and Loamy Sand}

The measured breakthrough curves (BTCs) generated from column transport experiments are presented in Figure S6. Two sets of column experiments were conducted for each of the experimental conditions investigated: (i) in quartz sand and (ii) in loamy sand. Bare Pd-NZVI exhibits substantial retention in both quartz and loamy sands, with elution levels (average $\left.C / C_{0}\right)<$ $15 \%$ at all IS investigated. In contrast, the surface-modified Pd-NZVI exhibit dramatically higher mobility. For example, at $3 \mathrm{mM}$ IS, the elution in quartz sand are $85 \%$ for JBR215-, 85\% for SFand $93 \%$ for CMC-coated Pd-NZVI. However, the extent of particle elution is lower in loamy sand 
with $60 \%$ elution for JBR215-, $63 \%$ for SF- and 72\% for CMC-coated Pd-NZVI. As well, at all other IS $(10,30,100 \mathrm{mM})$, more Pd-NZVI retention occurs in loamy sand compared to quartz sand (Figure S6). This result is consistent with previous studies (Kim et al., 2012; Petosa et al., 2013; Quevedo and Tufenkji, 2012) where the enhanced nanoparticle retention was attributed to geochemical heterogeneity of the loamy sand (e.g., presence of clay). Overall, as expected, the retention of coated Pd-NZVI increases (elution decreases) with IS due to more effective compression of the electrical double layers at the particle and sand surfaces (Figure S6).

\subsection{Assessing Pd-NZVI Transport Potential}

To semi-quantitatively compare the transport behavior of the bare and coated Pd-NZVI, the particle-collector attachment efficiency $\left(\alpha_{\mathrm{pc}}\right)$ was calculated (Equation 1) for all the experimental conditions examined. Two approaches were used to calculate $C / C_{0}$ : (i) by integration of the particle BTCs and (ii) the clean-bed approach which considers the average value of $C / C_{0}$ between PVs 1.8 2. Both methods were employed because, in some cases, a stable effluent particle concentration was not observed due to the dynamic nature of the BTCs. When the BTC is highly asymmetric (i.e., does not follow classical CFT-type behavior), the calculated $\alpha_{\mathrm{pc}}$ values should be considered valid for the purpose of semi-quantitative comparison. Moreover, two approaches (DLS and NTA) were used to calculate the hydrodynamic diameter of the Pd-NZVI particles. The combination of these two sizing techniques with two approaches to calculate $C / C_{0}$ results in four values of $\alpha$ for each experimental condition. All the calculated $\alpha_{\mathrm{pc}}$ values are presented in Table S4 and for clarity only one set (using DLS sizing + BTC-integration) of values is presented in graphical format in Figure 1. It is worth mentioning that, in this study, the $\alpha_{\mathrm{pc}}$ values are nearly identical when calculated using the two different approaches to evaluate $C / C_{0}$ (for a given particle size). However, 
there is some variation in the magnitude of $\alpha_{\mathrm{pc}}$ depending on which particle sizing technique (DLS vs NTA) is used, especially for the bare and CMC-coated particles, but generally the trends between the different surface modifiers, electrolyte solutions, and porous media are similar.

In quartz sand at $100 \mathrm{mM}$, the value of $\alpha_{\mathrm{pc}}$ of bare Pd-NZVI approaches the mass-transfer limited value $(\approx 1)$ and the particle deposition behaviour is termed favorable. The same experimental condition in loamy sand results in $\alpha_{\mathrm{pc}}>1$ when NTA-based sizes are considered which may be attributed to the technical limitations associated with NTA measurements and the contribution of physical straining. Indeed, smaller effluent sizes (compared to influent) for bare Pd-NZVI indicate preferential retention of larger aggregates (Table 1, Figure S4).

A key observation that can be made by inspection of Figure 1 is that surface modification of Pd-NZVI can significantly reduce $\alpha_{\mathrm{pc}}$, by at least one order of magnitude. At a given IS, for coated Pd-NZVI, the value of $\alpha_{\mathrm{pc}}$ is generally larger in loamy sand compared to quartz sand. The geochemical heterogeneity and potential for physical straining of the loamy sand could contribute to this observed higher retention as described in earlier studies where larger $\alpha_{\mathrm{pc}}$ values for different quantum dots and cerium dioxide nanoparticles were reported in the same loamy sand (Petosa et al., 2013; Quevedo and Tufenkji, 2012) than in quartz sand.

As described above, for the bare and CMC-coated Pd-NZVI, we note a difference in $\alpha_{\mathrm{pc}}$ depending on the particle sizing technique used (Table S4). At a given solution IS, a biased larger DLS size will yield an underestimated $\alpha_{\mathrm{pc}}$ value (and consequently over predict transport potential), whereas a biased smaller NTA size could overestimate the same. Hence, a suitable approach might be to use the range of $\alpha_{\mathrm{pc}}(\min -\max )$, for the different methods of estimation, at any given experimental condition of interest when predicting the transport potential of these polydisperse nanoparticles in the environment. An illustration of the predicted Pd-NZVI transport 
distance (based on $\alpha_{\mathrm{pc}}$ ) is presented in Figure S7 that clearly shows significant attenuation in travel distance in loamy sand.

\subsection{Effect of Particle Concentration on Pd-NZVI transport}

The comparative breakthrough behavior of bare and coated Pd-NZVI at two different influent mass concentrations $(0.15$ and $1 \mathrm{~g} / \mathrm{L})$ is presented in Figure 2. For bare Pd-NZVI, elution is negligible at both $1 \mathrm{~g} / \mathrm{L}$ and $0.15 \mathrm{~g} / \mathrm{L}$ and thus, bare Pd-NZVI is not suitable for real field application where a greater mobility to reach the contaminant zone is required. Similar conclusions have been reported from field and laboratory studies for bare and polymer-coated NZVI (He et al., 2010; Johnson et al., 2013; Kocur et al., 2014; Su et al., 2013). For CMC- and JBR215-coated Pd-NZVI, the elution is comparable at both particle concentrations, while the elution is slightly attenuated for SF-coated Pd-NZVI at higher particle concentration. Moreover, the deposition behavior is dynamic for SF-coated Pd-NZVI whereby the effluent concentration after $\sim 1.5$ PVs decreases with time. Concentration induced Pd-NZVI aggregation may be responsible for this dynamic deposition behaviour (discussed in the next section). These results thereby suggest that the selected surface

modifiers perform well even at higher Pd-NZVI concentration (i.e., at g/L) that are in the range of NZVI doses that are considered essential for site remediation (Jiemvarangkul et al., 2011; Phenrat et al., 2010). It is important to note that an increase in particle concentration induces substantial NZVI aggregation as observed in our previous study (Raychoudhury et al., 2012). The extent of concentration-dependent aggregation is depicted by the change in the intensity-weighted PSD (Figure S5) which shows considerable shift of the PSD towards larger sizes for both bare and coated Pd-NZVI. 
The calculated $\alpha_{\mathrm{pc}}$ at 0.15 and $1 \mathrm{~g} / \mathrm{L}$ Pd-NZVI mass concentration are compared in Figure 2c. Because Pd-NZVI aggregate sizes could not be estimated by NTA for the $1 \mathrm{~g} / \mathrm{L}$ suspensions, the $\alpha_{\mathrm{pc}}$ values referred here are those estimated on the basis of DLS particle size measurements. The difference in $\alpha_{\mathrm{pc}}$ is negligible for SF- and JBR215-coated Pd-NZVI. In contrast, the $\alpha_{\mathrm{pc}}$ for the CMC-stabilized Pd-NZVI is approximately an order of magnitude lower at $1 \mathrm{~g} / \mathrm{L}$ than at $0.15 \mathrm{~g} / \mathrm{L}$; this marked reduction in $\alpha_{\mathrm{pc}}$ can be attributed to the variation in the sizes of injected particles. The $\eta_{0}$ value does not change much within a large range of particle sizes $(147-1023 \mathrm{~nm})$ used in this study (Figure S8). For example, for JBR215-coated Pd-NZVI, the $\eta_{0}$ value does not change when the particle concentration is increased from $0.15 \mathrm{~g} / \mathrm{L}\left(d_{\mathrm{p}}=161 \mathrm{~nm}, \eta_{0}=0.03\right)$ to $1 \mathrm{~g} / \mathrm{L}\left(d_{\mathrm{p}}=1023 \mathrm{~nm}\right.$, $\eta_{0}=0.03$ ) (Figure S8). Hence, similar $\alpha_{\mathrm{pc}}$ values are obtained for these treatments. However, for CMC-coated Pd-NZVI, the considerably larger aggregate size $(>5 \mu \mathrm{m})$ at $1 \mathrm{~g} / \mathrm{L}$ results in a considerably higher $\eta_{0}$ value which significantly influences $\alpha_{\mathrm{pc}}$. It is worth noting that the calculated attachment efficiencies should be interpreted with caution due to challenges in adequately measuring particle size.

Although the steric stabilization of the selected surface modifiers against nanoparticle deposition is well established, the use of extended DLVO theory (which considers the contribution of steric interactions) is not straightforward. Moreover, measurement of the surface modifier layer thickness on the Pd-NZVI from TEM imaging is prone to artifacts due to sample preparation. Thus, in this study, we deemed it inappropriate to present extended DLVO calculations which would be based on a number of assumptions. Based on simple classical DLVO calculations, an increase in particle (aggregate) size results in an increase in the height of the repulsive energy barrier upon approach of a particle to a collector surface. An increase in particle concentration from 0.15 to 1 $\mathrm{g} / \mathrm{L}$ (and associated increase in aggregate size) thus results in increases in the height of the 
repulsive energy barrier in the interaction energy profile (by factors of 1.1,5.3 and 7.2, respectively for bare, CMC- and JBR215-coated Pd-NZVI) (Figure S9a, b, c). In contrast, SF-coated Pd-NZVI shows the opposite behavior, whereby the energy barrier becomes smaller with increasing particle concentration (and size) (Figure S9d). This may explain the observed higher deposition of SFcoated Pd-NZVI at $1 \mathrm{~g} / \mathrm{L}$ (versus $0.15 \mathrm{~g} / \mathrm{L}$ ). Furthermore, at $1 \mathrm{~g} / \mathrm{L}$, the higher elution observed for CMC-coated Pd-NZVI is consistent with a previous study (Saleh et al., 2007) that reports higher elution of triblock copolymer modified NZVI at higher particle concentration $(>1 \mathrm{~g} / \mathrm{L})$ in comparison to the elution obtained at lower particle concentration $(180 \mathrm{mg} / \mathrm{L})$. It is important to note that, for bare Pd-NZVI at $1 \mathrm{~g} / \mathrm{L}$, straining is a major retention mechanism as supported by the significant difference in DLS size in the influent $(2731 \mathrm{~nm})$ versus effluent suspension (866 nm) $\left(d_{\text {effluent }} / d_{\text {influent }} \leq 1\right)$ (Figure S10) and is in agreement with the straining argument made at $0.15 \mathrm{~g} / \mathrm{L}$ (Figure S4a). We previously reported physical straining of bare Pd-NZVI during transport through $651 \mu \mathrm{m}$ quartz sand (Basnet et al., 2013). A recent study (Raychoudhury et al., 2014) also demonstrates grain size dependent straining behavior with greater retention of CMC-coated NZVI in finer sand having a mean size similar to that used in this study, i.e., $256 \mu \mathrm{m}$. 


\subsection{Effect of Clay on Pd-NZVI Transport and Deposition}

To further investigate the role of clay present in the loamy sand on the observed deposition behavior, a separate series of transport experiments (at $10 \mathrm{mM}$ IS) was conducted whereby the quartz sand was supplemented with a model clay (kaolinite) at a concentration equivalent to that measured in the loamy sand (Quevedo and Tufenkji, 2012). Although kaolinite is not the exact same clay material as that present in the loamy sand (allophane), it was selected herein as a reasonable surrogate. The results of these transport experiments are compared with those obtained in clean quartz sand and loamy sand (Figure 3). It can be observed that Pd-NZVI elutes much earlier from the kaolinite supplemented quartz sand, likely due to an increase in pore water velocity as the addition of kaolinite may have altered the pore network connectivity that resulted in reduced bed porosity as seen by much lower effective porosity (0.12) and much higher dispersion coefficient $\left(0.75 \mathrm{~cm}^{2} / \mathrm{min}\right)$ (Table S2). Secondly, Pd-NZVI elution from the kaolinite supplemented sand is markedly lower compared to the identical conditions in quartz sand and loamy sand (Figure S11), and may be attributed to the heterogeneities created with the addition of clay and in agreement with previous observations reported by (Kim et al., 2012). Finally, dynamic deposition behavior is observed in the heterogeneous porous matrices compared to the quartz sand. A summary of transport studies demonstrating dynamic deposition behavior is presented in Table S5.

JBR215-coated Pd-NZVI exhibits "ripening" type deposition behavior whereby deposited particles act as additional collectors for the deposition of approaching particles resulting in a temporal decrease in $C / C_{0}$ (Figure $3 \mathrm{~d}, \mathrm{~g}$ ). Overall, the "ripening" behavior seems to be quite significant in loamy sand and kaolinite amended quartz sand. This result suggests that the addition of kaolinite in quartz sand may contribute to capturing the dynamic deposition behavior observed 
in loamy sand. We have shown previously, that for the same treatment (JBR215-coated Pd-NZVI), an increase in solution IS results in marked variation from a pseudo-ripening type behavior at lower IS $\left(10 \mathrm{mM} \mathrm{Na}^{+}\right)$to considerable ripening at higher IS (300 $\left.\mathrm{mM} \mathrm{Na}^{+}\right)$(Basnet et al., 2013) (Table S5). Likewise, for guar gum-coated NZVI, it was shown that the increase in approach velocity may also influence the dynamic behavior, whereby higher fluid velocity led to a clear ripening type breakthrough curve (Tiraferri and Sethi, 2009) (Table S5).

SF-coated Pd-NZVI exhibits "blocking" type deposition behavior whereby deposition of approaching particles is blocked by previously deposited particles, resulting in a temporal increase in $C / C_{0}$ (Figure 3b, e, h). The dynamic behavior is again amplified in the kaolinite amended column in the same manner as was observed for JBR215-coated Pd-NZVI, also mirroring the behavior in loamy sand. Such a "blocking" type behavior was previously observed in several studies (Table S5) including one that reports aggregation as a contributing factor for the observed dynamic behaviour for polyacrylic acid-coated NZVI (Raychoudhury et al., 2010). However, for SF-coated NZVI, the influence of aggregation is less important, as suggested by a smaller $d_{\mathrm{DLS}}$ at $10 \mathrm{mM}$ (Table 1). It is very likely that the complex physical and geochemical heterogeneity of the collector surface and variable affinities of the SF molecules for the collector surface might have contributed to the observed dynamic deposition process.

The deposition rate of CMC-coated Pd-NZVI appears constant in each granular matrix tested herein (Figure 3c, f, i). This behavior is consistent with previous observations for CMCstabilized NZVI through sand and sandy soil granular matrices (Basnet et al., 2013; He et al., 2009). With CMC coating, the steady-state breakthrough behavior is observed even at higher $(\mathrm{g} / \mathrm{L})$ NZVI concentration in a sand packed column (Kocur et al., 2013), pseudo-steady state to "blocking 
type" behavior in a kaolinite-supplemented column (Jung et al., 2014), and in column packed with different sand sizes (Raychoudhury et al., 2014).

\section{Conclusions}

The direct injection of Pd-NZVI into contaminated aquifers has been suggested as a promising technique for achieving rapid in situ remediation (Tratnyek and Johnson, 2006; Zhang, 2003). However, upon injection, the mobility of highly reactive Pd-NZVI may be influenced by several environmental factors pertaining to (i) nanoparticle surface chemistry and its aggregation state, (ii) aquifer grain physical and geochemical heterogeneities and (iii) ground water chemistry. This study has addressed such factors, the combination of which results in either improved or limited Pd-NZVI transport. Well-controlled column experiments were carried out to investigate the transport potential of bare and coated (rhamnolipid, soy flour and CMC) Pd-NZVI in granular porous matrices of varied complexity. Our results show that the selected surface modifiers are efficient in stabilizing and concurrently improving Pd-NZVI mobility in quartz sand and loamy sand. The direct application of surface modifiers to Pd-NZVI reduced the value of $\alpha_{\mathrm{pc}}$ by at least 1 order of magnitude (Basnet et al., 2013). At a given salt concentration, Pd-NZVI exhibits more affinity to the loamy sand compared to the quartz sand, emphasizing the critical role that grain surface geochemical heterogeneity may play in controlling Pd-NZVI mobility. The role of clay was further examined by supplementing the quartz sand with a model clay. Interestingly, surfacemodified Pd-NZVI exhibits a distinctive behavior for each type of surface coating examined; with JBR215 coating, the particle deposition rate tends to decrease with time (ripening type behavior); with SF coating, the particle deposition rate tends to increase with time (blocking type behavior); 
and with $\mathrm{CMC}$ coating, the particle deposition rate is relatively constant with time. These trends are particularly clear in the heterogeneous matrices.

The observed variation in the affinity of coated Pd-NZVI for heterogeneous collector surfaces (loamy sand) in contrast to the relatively homogeneous quartz sand (on which several previous studies are based) contributes to the uncertainty associated to predicting and/or engineering Pd-NZVI mobility for a real field application. Therefore, site specific transport potential assessment considering both hydrogeology and geochemistry of the site is necessary. This study provides a starting point for understanding to what extent the variation in aquifer heterogeneity coupled with a fluctuation in ground water chemistry can influence Pd-NZVI transport behavior. 


\section{Acknowledgements}

This research was supported by NSERC Strategic Grant no. 365253 and NSERC Discovery, Golder Associates Ltd., FQRNT, a MEDA to M.B., and the CRC program. C.D.T. was supported by a McGill SURE award. 


\section{References}

Basnet, M., Ghoshal, S., Tufenkji, N., 2013. Rhamnolipid Biosurfactant and Soy Protein Act as Effective Stabilizers in the Aggregation and Transport of Palladium-Doped Zerovalent Iron Nanoparticles in Saturated Porous Media. Environmental Science \& Technology 47 (23), 13355-13364.

Cornelis, G., Pang, L., Doolette, C., Kirby, J.K., McLaughlin, M.J., 2013. Transport of silver nanoparticles in saturated columns of natural soils. Science of the Total Environment 463-464 (0), 120-130.

Domingos, R.F., Tufenkji, N., Wilkinson, K.J., 2009. Aggregation of Titanium Dioxide Nanoparticles: Role of a Fulvic Acid. Environmental Science \& Technology 43 (5), 1282-1286.

Fatisson, J., Ghoshal, S., Tufenkji, N., 2010. Deposition of Carboxymethylcellulose-Coated Zero-Valent Iron Nanoparticles onto Silica: Roles of Solution Chemistry and Organic Molecules. Langmuir 26 (15), 12832-12840. He, F., Zhang, M., Qian, T., Zhao, D., 2009. Transport of carboxymethyl cellulose stabilized iron nanoparticles in porous media: Column experiments and modeling. Journal of Colloid and Interface Science 334 (1), 96-102.

He, F., Zhao, D., Paul, C., 2010. Field assessment of carboxymethyl cellulose stabilized iron nanoparticles for in situ destruction of chlorinated solvents in source zones. Water Research 44 (7), 2360-2370.

Jaisi, D.P., Elimelech, M., 2009. Single-Walled Carbon Nanotubes Exhibit Limited Transport in Soil Columns. Environmental Science \& Technology 43 (24), 9161-9166.

Jiemvarangkul, P., Zhang, W.-X., Lien, H.-L., 2011. Enhanced transport of polyelectrolyte stabilized nanoscale zerovalent iron (nZVI) in porous media. Chemical Engineering Journal 170 (2-3), 482-491.

Johnson, R.L., Nurmi, J.T., O’Brien Johnson, G.S., Fan, D., O’Brien Johnson, R.L., Shi, Z., Salter-Blanc, A.J., Tratnyek, P.G., Lowry, G.V., 2013. Field-Scale Transport and Transformation of Carboxymethylcellulose-Stabilized Nano Zero-Valent Iron. Environmental Science \& Technology 47 (3), 1573-1580.

Johnson, W.P., Li, X., Yal, G., 2007. Colloid Retention in Porous Media: Mechanistic Confirmation of Wedging and Retention in Zones of Flow Stagnation. Environmental Science \& Technology 41 (4), 1279-1287.

Jung, B., O'Carroll, D., Sleep, B., 2014. The influence of humic acid and clay content on the transport of polymercoated iron nanoparticles through sand. Science of the Total Environment 496, 155-164.

Kanel, S., Nepal, D., Manning, B., Choi, H., 2007. Transport of surface-modified iron nanoparticle in porous media and application to arsenic(III) remediation. Journal of Nanoparticle Research 9 (5), 725-735.

Kim, H.J., Phenrat, T., Tilton, R.D., Lowry, G.V., 2012. Effect of kaolinite, silica fines and pH on transport of polymer-modified zero valent iron nano-particles in heterogeneous porous media. Journal of Colloid and Interface Science 370 (1), 1-10.

Kocur, C.M., Chowdhury, A.I., Sakulchaicharoen, N., Boparai, H.K., Weber, K.P., Sharma, P., Krol, M.M., Austrins, L., Peace, C., Sleep, B.E., O'Carroll, D.M., 2014. Characterization of nZVI Mobility in a Field Scale Test. Environmental Science \& Technology 48 (5), 2862-2869.

Kocur, C.M., O'Carroll, D.M., Sleep, B.E., 2013. Impact of nZVI stability on mobility in porous media. Journal of Contaminant Hydrology 145 (0), 17-25.

Laumann, S., Micić, V., Hofmann, T., 2014. Mobility enhancement of nanoscale zero-valent iron in carbonate porous media through co-injection of polyelectrolytes. Water Research 50, 70-79.

Lowry, G.V., Gregory, K.B., Apte, S.C., Lead, J.R., 2012. Transformations of Nanomaterials in the Environment. Environmental Science \& Technology 46 (13), 6893-6899.

Nobbmann, U., Connah, M., Fish, B., Varley, P., Gee, C., Mulot, S., Chen, J., Zhou, L., Lu, Y., Sheng, F., Yi, J., Harding, S.E., 2007. Dynamic light scattering as a relative tool for assessing the molecular integrity and stability of monoclonal antibodies. Biotechnology and Genetic Engineering Reviews 24, 117-128.

Pelley, A.J., Tufenkji, N., 2008. Effect of particle size and natural organic matter on the migration of nano- and microscale latex particles in saturated porous media. Journal of Colloid and Interface Science 321 (1), 74-83.

Petosa, A.R., Brennan, S.J., Rajput, F., Tufenkji, N., 2012. Transport of two metal oxide nanoparticles in saturated granular porous media: Role of water chemistry and particle coating. Water Research 46 (4), 1273-1285.

Petosa, A.R., Jaisi, D.P., Quevedo, I.R., Elimelech, M., Tufenkji, N., 2010. Aggregation and Deposition of Engineered Nanomaterials in Aquatic Environments: Role of Physicochemical Interactions. Environmental Science \& Technology 44 (17), 6532-6549.

Petosa, A.R., Öhl, C., Rajput, F., Tufenkji, N., 2013. Mobility of nanosized cerium dioxide and polymeric capsules in quartz and loamy sands saturated with model and natural groundwaters. Water Research 47 (15), 5889-5900.

Phenrat, T., Kim, H.-J., Fagerlund, F., Illangasekare, T., Lowry, G.V., 2010. Empirical correlations to estimate agglomerate size and deposition during injection of a polyelectrolyte-modified $\mathrm{Fe} 0$ nanoparticle at high particle concentration in saturated sand. Journal of Contaminant Hydrology 118 (3-4), 152-164. 
Phenrat, T., Kim, H.-J., Fagerlund, F., Illangasekare, T., Tilton, R.D., Lowry, G.V., 2009. Particle Size Distribution, Concentration, and Magnetic Attraction Affect Transport of Polymer-Modified Fe0 Nanoparticles in Sand Columns. Environmental Science \& Technology 43 (13), 5079-5085.

Phenrat, T., Saleh, N., Sirk, K., Kim, H.-J., Tilton, R., Lowry, G., 2008. Stabilization of aqueous nanoscale zerovalent iron dispersions by anionic polyelectrolytes: adsorbed anionic polyelectrolyte layer properties and their effect on aggregation and sedimentation. Journal of Nanoparticle Research 10 (5), 795-814.

Phenrat, T., Saleh, N., Sirk, K., Tilton, R.D., Lowry, G.V., 2006. Aggregation and Sedimentation of Aqueous Nanoscale Zerovalent Iron Dispersions. Environmental Science \& Technology 41 (1), 284-290.

Quevedo, I.R., Tufenkji, N., 2012. Mobility of Functionalized Quantum Dots and a Model Polystyrene Nanoparticle in Saturated Quartz Sand and Loamy Sand. Environmental Science \& Technology 46 (8), 4449-4457.

Raychoudhury, T., Naja, G., Ghoshal, S., 2010. Assessment of transport of two polyelectrolyte-stabilized zerovalent iron nanoparticles in porous media. Journal of Contaminant Hydrology 118 (3-4), 143-151.

Raychoudhury, T., Tufenkji, N., Ghoshal, S., 2012. Aggregation and deposition kinetics of carboxymethyl cellulosemodified zero-valent iron nanoparticles in porous media. Water Research 46 (6), 1735-1744.

Raychoudhury, T., Tufenkji, N., Ghoshal, S., 2014. Straining of polyelectrolyte-stabilized nanoscale zero valent iron particles during transport through granular porous media. Water Research 50 (0), 80-89.

Saleh, N., Kim, H.-J., Phenrat, T., Matyjaszewski, K., Tilton, R.D., Lowry, G.V., 2008. Ionic Strength and Composition Affect the Mobility of Surface-Modified Fe ${ }^{0}$ Nanoparticles in Water-Saturated Sand Columns. Environmental Science \& Technology 42 (9), 3349-3355.

Saleh, N., Sirk, K., Liu, Y., Phenrat, T., Dufour, B., Matyjaszewski, K., Tilton, R.D., Lowry, G.V., 2007. Surface modifications enhance nanoiron transport and NAPL targeting in saturated porous media. Environmental Engineering Science 24 (1), 45-57.

Schrick, B., Hydutsky, B.W., Blough, J.L., Mallouk, T.E., 2004. Delivery Vehicles for Zerovalent Metal Nanoparticles in Soil and Groundwater. Chemistry of Materials 16 (11), 2187-2193.

Su, C., Puls, R.W., Krug, T.A., Watling, M.T., O'Hara, S.K., Quinn, J.W., Ruiz, N.E., 2013. Travel distance and transformation of injected emulsified zerovalent iron nanoparticles in the subsurface during two and half years.

Water Research 47 (12), 4095-4106.

Tiraferri, A., Chen, K.L., Sethi, R., Elimelech, M., 2008. Reduced aggregation and sedimentation of zero-valent iron nanoparticles in the presence of guar gum. Journal of Colloid and Interface Science 324 (1-2), 71-79.

Tiraferri, A., Sethi, R., 2009. Enhanced transport of zerovalent iron nanoparticles in saturated porous media by guar gum. Journal of Nanoparticle Research 11 (3), 635-645.

Tratnyek, P.G., Johnson, R.L., 2006. Nanotechnologies for environmental cleanup. Nano Today 1 (2), $44-48$.

Tufenkji, N., Elimelech, M., 2004. Correlation Equation for Predicting Single-Collector Efficiency in Physicochemical Filtration in Saturated Porous Media. Environmental Science \& Technology 38 (2), $529-536$.

Yao, K.-M., Habibian, M.T., O'Melia, C.R., 1971. Water and waste water filtration. Concepts and applications. Environmental Science \& Technology 5 (11), 1105-1112.

Zhang, W.-X., 2003. Nanoscale Iron Particles for Environmental Remediation: An Overview. Journal of Nanoparticle Research 5 (3), 323-332.

Zhao, L., Peralta-Videa, J.R., Hernandez-Viezcas, J.A., Hong, J., Gardea-Torresdey, J.L., 2012. Transport and retention behavior of $\mathrm{ZnO}$ nanoparticles in two natural soils: Effect of surface coating and soil composition. Journal of Nano Research 17, 229-242. 
Figures and Tables
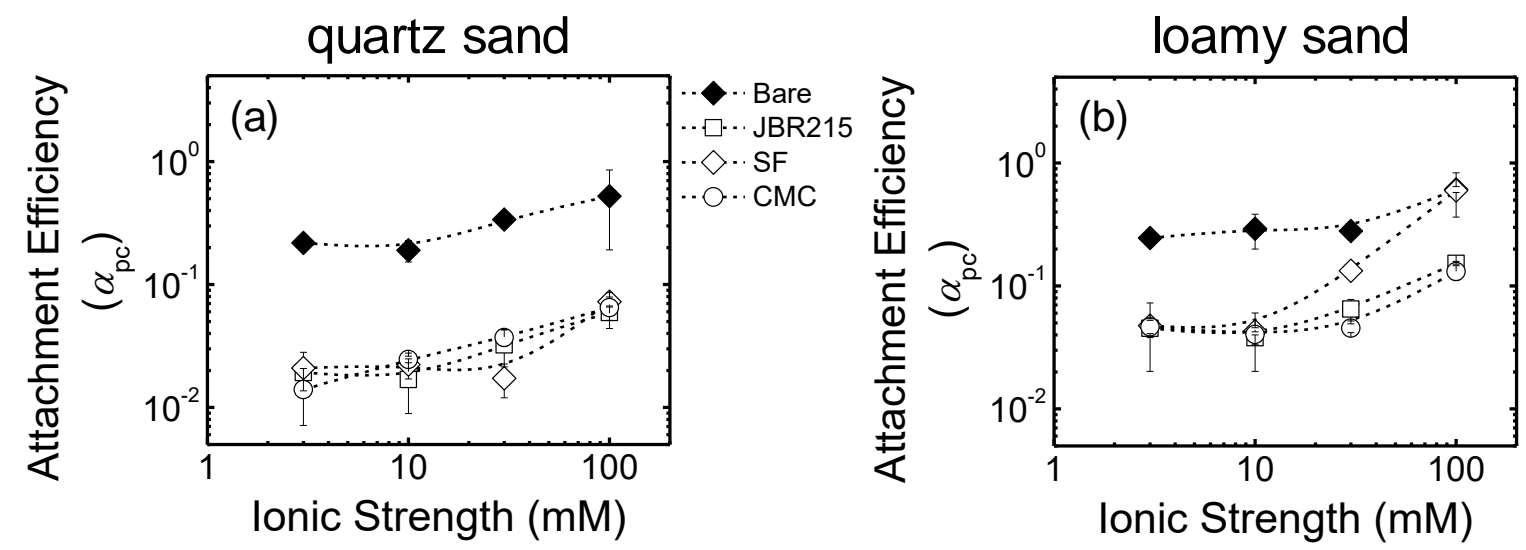

Fig. 1. Calculated particle-collector attachment efficiency $\left(\alpha_{p c}\right)$ as a function of solution IS for bare, JBR215-, SF- and CMC-coated Pd-NZVI suspensions at an influent concentration of $150 \mathrm{mg} / \mathrm{L}$ in (a) quartz sand and (b) loamy sand. The calculation is based on DLS measured particle hydrodynamic diameter with $C / C_{0}$ calculated from the numerical integration of the BTC. The dashed lines are included to guide the eye. 

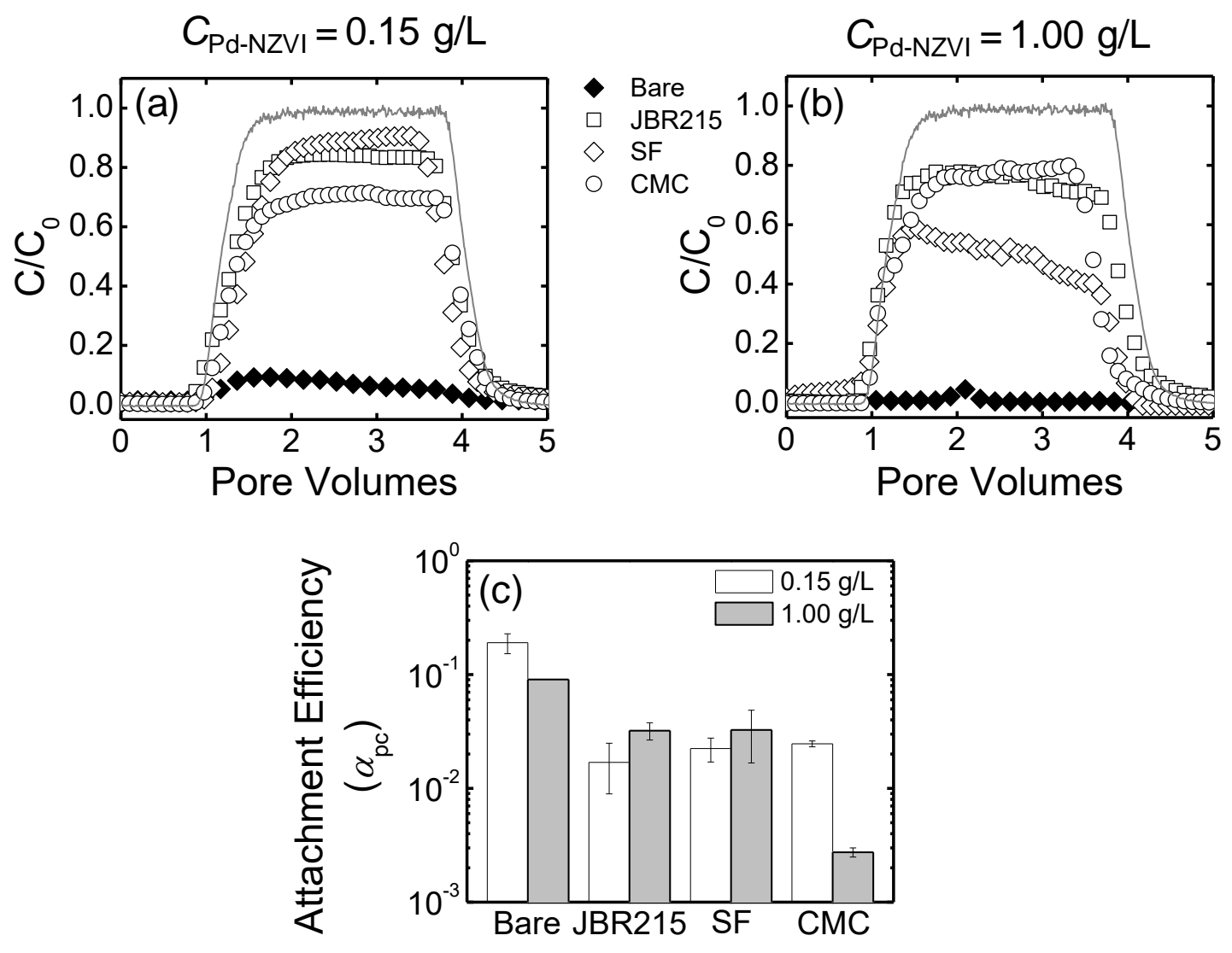

Fig. 2. Effect of influent Pd-NZVI mass concentration on the elution of bare, CMC-, JBR215- and SFcoated Pd-NZVI in a quartz sand-packed column at $10 \mathrm{mM} \mathrm{IS:} \mathrm{(a)} \mathrm{at} 0.15 \mathrm{~g} / \mathrm{L}$ and (b) at $1.0 \mathrm{~g} / \mathrm{L}$. (c) Calculated particle-collector attachment efficiency $\left(\alpha_{p c}\right)$ based on DLS-measured particle (aggregate) sizes with $C / C_{0}$ calculated from the numerical integration of the BTC. 

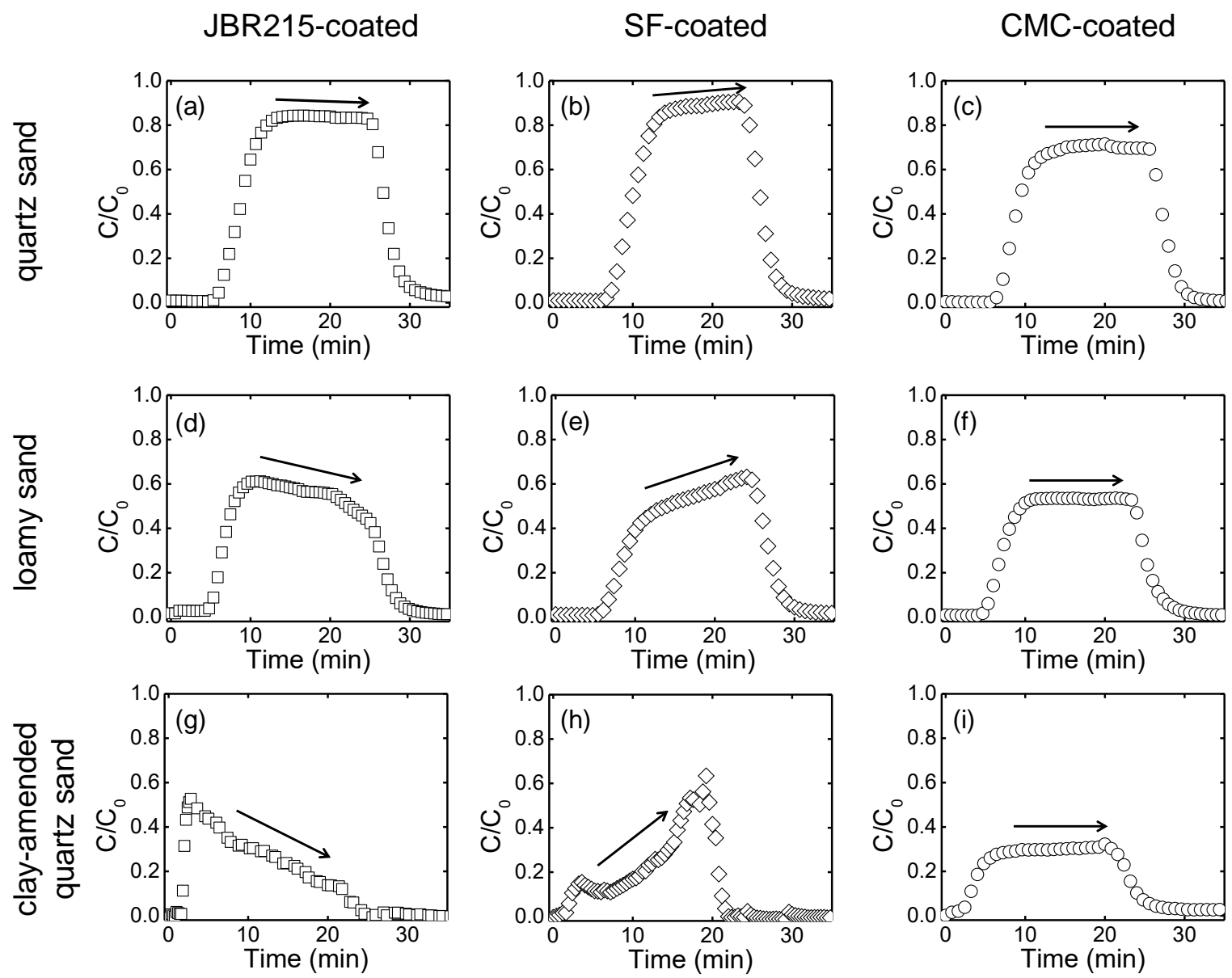

Fig. 3. Measured breakthrough curves for JBR215-coated Pd-NZVI (a, d, g), SF-coated Pd-NZVI (b, e, $b$ ) and CMC-coated Pd-NZVI ( $, f, i)$ in quartz sand $(a, b, c)$, loamy sand $(d, e, f)$ and clay (kaolinite)supplemented quartz sand $(g, h, i)$ at $10 \mathrm{mMIS}$. Other experimental conditions are: packed bed length

$8.1 \mathrm{~cm}$, approach (Darcy) velocity $7.46 \times 10^{-5} \mathrm{~m} / \mathrm{s}$ and Pd-NZVI concentration $(0.15 \mathrm{~g} / \mathrm{L})$. 
Table 1. Physico-chemical characterization of Pd-NZVI used in the transport experiments.

\begin{tabular}{|c|c|c|c|c|c|c|c|c|c|c|c|}
\hline \multirow[b]{2}{*}{ particle type } & \multirow[b]{2}{*}{$\begin{array}{l}\text { ionic strength } \\
(\mathrm{mM} \mathrm{NaCl})\end{array}$} & \multicolumn{3}{|c|}{ influent suspension } & \multirow[b]{2}{*}{$\begin{array}{l}\text { column } \\
\text { type }\end{array}$} & \multicolumn{3}{|c|}{ effluent suspension } & \multicolumn{3}{|c|}{ NTA size analysis (influent suspension) } \\
\hline & & $\begin{array}{c}\text { EPM } \\
(\mu \mathrm{m} . \mathrm{cm} / \mathrm{V} . \mathrm{s})\end{array}$ & $\begin{array}{l}d_{\mathrm{DLS}} \\
(\mathrm{nm})\end{array}$ & PDI & & $\begin{array}{c}\text { EPM } \\
(\mu \mathrm{m} . \mathrm{cm} / \mathrm{V} . \mathrm{s})\end{array}$ & $\begin{array}{l}d_{\mathrm{DLS}} \\
(\mathrm{nm})\end{array}$ & $\overline{P D I}$ & $\begin{array}{l}d_{10} \\
(\mathrm{~nm})\end{array}$ & $\begin{array}{c}d_{50}\left(\text { or } d_{\text {NTA }}\right) \\
(n \mathrm{~m})\end{array}$ & $\begin{array}{l}d_{90} \\
(n m)\end{array}$ \\
\hline \multirow[t]{8}{*}{ Bare } & 3 & $-1.9 \pm 0.3$ & $1043 \pm 126$ & 0.6 & quartz sand & $-2.4 \pm 0.1$ & $515 \pm 53$ & 0.7 & $144 \pm 21$ & $239 \pm 33$ & $373 \pm 49$ \\
\hline & & & & & loamy sand & $-1.6 \pm 0.2$ & $596 \pm 76$ & 0.6 & & & \\
\hline & 10 & $-2.4 \pm 0.2$ & $1389 \pm 235$ & 0.4 & quartz sand & $-2.9 \pm 0.1$ & $973 \pm 82$ & 0.3 & $200 \pm 22$ & $306 \pm 23$ & $411 \pm 63$ \\
\hline & & & & & loamy sand & $-2.3 \pm 0.1$ & $605 \pm 51$ & 0.5 & & & \\
\hline & 30 & $-1.6 \pm 0.1$ & $1167 \pm 100$ & 0.5 & quartz sand & $-1.0 \pm 0.2$ & $829 \pm 204$ & 0.6 & $234 \pm 24$ & $358 \pm 27$ & $559 \pm 95$ \\
\hline & & & & & loamy sand & $-1.0 \pm 0.1$ & $618 \pm 52$ & 0.5 & & & \\
\hline & 100 & $-1.4 \pm 0.1$ & $1332 \pm 223$ & 0.5 & quartz sand & $-1.5 \pm 0.1$ & $920 \pm 196$ & 0.7 & $251 \pm 21$ & $399 \pm 71$ & $537 \pm 100$ \\
\hline & & & & & loamy sand & $-1.0 \pm 0.3$ & $516 \pm 56$ & 0.4 & & & \\
\hline \multirow[t]{8}{*}{ JBR215-coated } & 3 & $-3.8 \pm 0.1$ & $179 \pm 5$ & 0.4 & quartz sand & $-3.5 \pm 0.1$ & $172 \pm 3$ & 0.3 & $81 \pm 18$ & $210 \pm 17$ & $385 \pm 53$ \\
\hline & & & & & loamy sand & $-3.6 \pm 0.1$ & $175 \pm 5$ & 0.3 & & & \\
\hline & 10 & $-3.7 \pm 0.1$ & $161 \pm 54$ & 0.3 & quartz sand & $-3.7 \pm 0.1$ & $141 \pm 41$ & 0.3 & $90 \pm 18$ & $191 \pm 23$ & $348 \pm 64$ \\
\hline & & & & & loamy sand & $-3.5 \pm 0.1$ & $171 \pm 26$ & 0.3 & & & \\
\hline & 30 & $-3.6 \pm 0.1$ & $181 \pm 3$ & 0.5 & quartz sand & $-3.6 \pm 0.2$ & $139 \pm 3$ & 0.4 & $97 \pm 18$ & $211 \pm 39$ & $397 \pm 29$ \\
\hline & & & & & loamy sand & $-3.3 \pm 0.2$ & $171 \pm 4$ & 0.4 & & & \\
\hline & 100 & $-2.1 \pm 0.1$ & $263 \pm 19$ & 0.6 & quartz sand & $-2.1 \pm 0.1$ & $178 \pm 3$ & 0.4 & $103 \pm 13$ & $185 \pm 9$ & $323 \pm 8$ \\
\hline & & & & & loamy sand & $-1.9 \pm 0.1$ & $252 \pm 15$ & 0.5 & & & \\
\hline \multirow[t]{8}{*}{ SF-coated } & 3 & $-2.2 \pm 0.1$ & $196 \pm 10$ & 0.3 & quartz sand & $-1.8 \pm 0.1$ & $167 \pm 38$ & 0.3 & $34 \pm 1$ & $107 \pm 8$ & $273 \pm 32$ \\
\hline & & & & & loamy sand & $-2.1 \pm 0.1$ & $188 \pm 3$ & 0.3 & & & \\
\hline & 10 & $-2.5 \pm 0.1$ & $147 \pm 6$ & 0.4 & quartz sand & $-2.3 \pm 0.1$ & $155 \pm 3$ & 0.3 & $44 \pm 15$ & $152 \pm 63$ & $345 \pm 78$ \\
\hline & & & & & loamy sand & $-2.1 \pm 0.1$ & $130 \pm 6$ & 0.3 & & & \\
\hline & 30 & $-2.0 \pm 0.1$ & $159 \pm 3$ & 0.3 & quartz sand & $-2.1 \pm 0.1$ & $146 \pm 3$ & 0.3 & $48 \pm 15$ & $120 \pm 21$ & $264 \pm 9$ \\
\hline & & & & & loamy sand & $-2.3 \pm 0.3$ & $187 \pm 8$ & 0.3 & & & \\
\hline & 100 & $-1.2 \pm 0.1$ & $253 \pm 34$ & 0.4 & quartz sand & $-1.1 \pm 0.1$ & $180 \pm 11$ & 0.3 & $80 \pm 27$ & $194 \pm 64$ & $398 \pm 48$ \\
\hline & & & & & loamy sand & $-0.9 \pm 0.1$ & $286 \pm 36$ & 0.4 & & & \\
\hline \multirow[t]{8}{*}{ CMC-coated } & 3 & $-4.5 \pm 0.0$ & $647 \pm 91$ & 0.7 & quartz sand & $-4.4 \pm 0.1$ & $579 \pm 63$ & 0.7 & $103 \pm 26$ & $229 \pm 41$ & $363 \pm 26$ \\
\hline & & & & & loamy sand & $-4.2 \pm 0.1$ & $707 \pm 36$ & 0.7 & & & \\
\hline & 10 & $-4.3 \pm 0.1$ & $1415 \pm 189$ & 0.6 & quartz sand & $-4.1 \pm 0.1$ & $1492 \pm 141$ & 0.5 & $118 \pm 42$ & $278 \pm 32$ & $518 \pm 51$ \\
\hline & & & & & loamy sand & $-4.2 \pm 0.1$ & $1401 \pm 82$ & 0.5 & & & \\
\hline & 30 & $-3.9 \pm 0.1$ & $1298 \pm 94$ & 0.6 & quartz sand & $-3.9 \pm 0.2$ & $1278 \pm 63$ & 0.6 & $172 \pm 22$ & $300 \pm 26$ & $497 \pm 129$ \\
\hline & & & & & loamy sand & $-3.8 \pm 0.1$ & $799 \pm 65$ & 0.7 & & & \\
\hline & 100 & $-2.5 \pm 0.1$ & $1499 \pm 175$ & 0.6 & quartz sand & $-2.5 \pm 0.0$ & $495 \pm 46$ & 0.6 & $179 \pm 33$ & $280 \pm 9$ & $397 \pm 60$ \\
\hline & & & & & loamy sand & $-2.5 \pm 0.1$ & $1115 \pm 148$ & 0.5 & & & \\
\hline Bare* $^{*}$ & 10 & $-2.1 \pm 0.1$ & $2731 \pm 303$ & 0.5 & quartz sand & $-1.0 \pm 0.2$ & $866 \pm 306$ & 0.4 & & & \\
\hline JBR215-coated ${ }^{*}$ & 10 & $-4.0 \pm 0.1$ & $1023 \pm 48$ & 0.3 & quartz sand & $-4.0 \pm 0.1$ & $853 \pm 35$ & 0.4 & & n.d. & \\
\hline SF-coated ${ }^{*}$ & 10 & $-1.2=0.2$ & $1841 \pm 104$ & 0.4 & quartz sand & $-1.1 \pm 0.1$ & $1154 \pm 60$ & 0.3 & & & \\
\hline CMC-coated ${ }^{*}$ & 10 & $-4.8 \pm 0.1$ & $5916 \pm 444$ & 0.3 & quartz sand & $-5.5 \pm 0.1$ & $8295 \pm 163$ & 0.6 & & & \\
\hline
\end{tabular}

